\title{
¿Aplazando la llegada del primer hijo? \\ Un estudio cualitativo sobre las percepciones en torno al retraso de la fecundidad
}

\author{
Viviana González Hincapié \\ Universidad Complutense de Madrid. Facultad de Ciencias Políticas y Sociología \\ vivianag@ucm.es
}

\section{María Teresa López López}

Universidad Complutense de Madrid. Facultad de Ciencias Económicas y Empresariales mtlopezl@ccee.ucm.es

\section{Resumen}

En un escenario de fecundidad muy baja entre las bajas como el español, caracterizado por una transición al aplazamiento en la tenencia del primer hijo, este artículo aborda las percepciones y las valoraciones más relevantes que estarían influyendo en el retraso de la tenencia del primer hijo entre las personas de 25 a 45 años residentes en la Comunidad de Madrid. A partir de la Teoría del Comportamiento Planificado (TPB) aplicado al ámbito de las decisiones reproductivas, y mediante los resultados de 16 entrevistas en profundidad realizadas en 2017 a mujeres y hombres, se indaga si la percepción de efectos negativos esperados, de presiones sociales normativas y la dependencia de circunstancias externas, están incidiendo directamente sobre la intención de aplazar la tenencia del primer hijo. Con la integración de aportaciones relevantes de la literatura sobre los determinantes de la fecundidad, se aporta evidencia cualitativa de los factores que inciden sobre este retraso. La percepción de penalización para la mujer en el ámbito laboral remunerado asociada a la llegada de los hijos — especialmente con relación al ascenso y a la progresión profesional—, la percepción de costes personales en términos de ocio y libertad de movimiento, y el no alcance de la estabilidad económica considerada como idónea para la crianza de los hijos hasta edades tardías estarían incidiendo en el retraso de la tenencia del primer hijo. La presión social normativa tendría menor incidencia, mientras que la alta valoración atribuida a la autonomía individual estaría influyendo en las intenciones de aplazamiento.

Palabras clave: aplazamiento de la fecundidad; aplazamiento de la maternidad; baja fecundidad; Teoría del Comportamiento Planificado; intenciones reproductivas; penalización por maternidad; segunda transición demográfica; valores; entrevistas cualitativas en profundidad; España 
Abstract. Delaying the arrival of the first child? A qualitative study on the perceptions around childbearing postponement.

In a scenario of lowest-low fertility levels like the Spanish one, characterized by a postponement transition, especially for first births, this paper looks into the most relevant perceptions and values which may be affecting the childbearing delay for the first child among people aged between 25 and 45 in the Community of Madrid. Based upon the Theory of Planned Behavior (TPB) applied to the fertility decision-making process, and by means of 16 in-depth qualitative interviews carried out in 2017 among women and men, the article aims at inquiring whether the expected negative outcomes of having a child, the perceived normative social pressures and the perception of dependence on external factors, are directly influencing the decision of having a first child. This article includes significant contributions from studies about fertility determinants and provides qualitative evidence about the factors that have an impact on this delay. The perceived motherhood penalty in the labor market, specially related to career progression, the perceived negative outcomes in terms of leisure time and freedom of movement, and the late achievement of the economic stability considered as ideal in order to have a child, may be having an impact on the postponement of the first childbearing. Our results suggest that social normative pressure may be less influential in Spain, while the high value attributed to individual autonomy may contribute to the delay of parenthood.

Keywords: fertility postponement; motherhood postponement; low fertility; theory of planned behavior; fertility intentions; motherhood penalty; second demographic transition; values; in-depth qualitative interviews; Spain

\begin{aligned} & \multicolumn{2}{c}{ Sumario } \\ & 1. Introducción 6. Discusión \\ & 2. Marco teórico 7. Conclusiones \\ & 3. Preguntas de investigación e hipótesis Agradecimientos \\ & 4. Diseño metodológico Financiación \\ & 5. Resultados Referencias bibliográficas \end{aligned}

\section{Introducción}

El foco central de los estudios que abordan el tempo - uno de los dos componentes centrales de la fecundidad, junto al quantum — ha sido el aplazamiento creciente en la tenencia de los hijos (Balbo et al., 2013). Dicho retraso constituye uno de los rasgos de los países avanzados con baja fecundidad, entre los que se encuentra España (Beaujouan y Sobotka, 2017), con niveles de fecundidad inferiores a 1,3 se cuenta entre los de fecundidad más baja entre las bajas (Billari y Kohler, 2004). Y aunque los nacimientos tardíos no son algo nuevo en la historia, sí lo es el hecho de que una parte importante de estos se registre para los primeros nacimientos. España ocuparía una de las primeras posiciones de la Unión Europea en cuanto al porcentaje de madres que tienen su primer 
hijo a partir de los 40 años (Castro Martín et al., 2018), y presentaría, junto a Italia, la edad media más elevada de las mujeres al nacimiento del primer hijo en el marco de toda la Unión Europea: 31 años en 2018 (Eurostat, 2020). Se habría pasado de una edad media al nacimiento del primer hijo de 25,25 años en 1975 (INE, 2019b) a la cifra de 31 años en 2018. Así pues, España formaría parte de aquellos países en los que se habría producido una «transición hacia el aplazamiento» ("postponement transition») (Kohler et al., 2002).

El retraso en el calendario reproductivo conduciría a una reducción de la fecundidad a través de mecanismos distintos: ${ }^{1}$ el aumento de la proporción de personas sin hijos debido al mayo riesgo de infecundidad biológica que trae consigo el aplazamiento de las decisiones reproductivas más allá de ciertas edades; el aumento de la infecundidad voluntaria, y la reducción del número total de hijos de aquellos que sí los tienen, debido al menor tiempo disponible para los nuevos nacimientos y a la reducción de la fertilidad con el paso de los años - no compensada por las técnicas de reproducción asistida y las adopciones- (Beaujouan y Sobotka, 2017; Castro Martín et al., 2018).

Estamos ante una tendencia demográfica del todo relevante, no solo por sus consecuencias sobre el balance de baja fecundidad final, sino también porque puede ser un indicador clave de cambio social respecto a la transición a la vida adulta y a la configuración de nuevas unidades familiares, así como de cambio de valores. También puede estar indicando la existencia de constreñimientos y barreras estructurales en ámbitos como el laboral, en los que sería la mujer la que se vería especialmente afectada. Comprender las causas de un fenómeno tan complejo resulta del todo relevante, no solo para seguir avanzando en el debate académico, sino también con el objetivo de contribuir a informar la configuración de políticas públicas, tanto europeas como españolas, en el escenario demográfico actual.

A partir de evidencia cualitativa procedente de 16 entrevistas en profundidad, este artículo busca efectuar una aportación relevante al debate sobre los factores que inciden en el retraso de las decisiones reproductivas. Nos centraremos en las percepciones y las valoraciones más relevantes que estarían influyendo en el retraso de la tenencia del primer hijo entre las personas de 25 a 45 años residentes en la Comunidad de Madrid. Abordamos una perspectiva micro de las intenciones reproductivas, pero sin perder de vista su interrelación con factores macro y con algunos de los marcos teóricos más relevantes que se han utilizado para explicar la transición hacia una baja fecundidad en las sociedades avanzadas.

El artículo se estructura del siguiente modo. En la segunda parte, se efectúa una aproximación a la Teoría del Comportamiento Planificado en el marco de la configuración de las intenciones reproductivas en el nivel micro. A su vez, se establecen vínculos entre los elementos centrales de la teoría y algunas aportaciones relevantes de la literatura sobre la fecundidad. La tercera parte

1. Una discusión introductoria acerca del efecto tempo sobre la caída del ICF puede encontrarse en Liefbroer et al. (2015). 
recoge las preguntas de investigación y las hipótesis planteadas. La cuarta está dedicada al diseño metodológico. La quinta recoge los resultados del análisis de las entrevistas en profundidad. La sexta plantea la discusión de los resultados obtenidos a la luz de aportaciones relevantes de la literatura, a la vez que aborda las limitaciones del estudio. Finalmente, se plantean las conclusiones principales de la investigación.

\section{Marco teórico}

Las causas del aplazamiento en la tenencia de los hijos son complejas y multifactoriales. En el marco general de los determinantes de la fecundidad, las investigaciones han abordado factores relativos a las circunstancias que afectan la toma de decisiones reproductivas individualmente o en pareja (nivel micro); otras han prestado atención a la influencia del entorno social próximo (nivel meso); la mayoría se ha centrado en los aspectos institucionales o culturales (nivel macro) (Balbo et al., 2013).

Investigaciones recientes sobre fecundidad han reconocido la necesidad de conceptualizarla vinculando elementos micro y macro: las condiciones macro influirían sobre las decisiones reproductivas de los individuos, y la tenencia o no de hijos sería el resultado de este proceso de toma de decisión. Los procesos de decisiones individuales y de la pareja relacionadas con la fecundidad adquieren así un papel relevante de cara a una mejor comprensión de los fenómenos micro y macro (Liefbroer et al., 2015).

Una parte de la literatura sobre los factores micro ha prestado atención a las consideraciones y las percepciones que forman parte de esos procesos de toma de decisiones reproductivas. La mayoría de estos estudios tienen su punto de partida en teorías provenientes de la psicología social, como el modelo TDIB (rasgos, deseos, intenciones y comportamientos, en la sigla en inglés) de Miller y Pasta (Miller y Pasta, 1994; Miller, 2011a), cuyo uso ha sido limitado en estudios demográficos. Frente a ella, la Teoría del Comportamiento Planificado (Theory of Planned Behavior - TPB) ha sido el enfoque más utilizado para abordar la configuración de las intenciones reproductivas en el nivel micro. Desde hace poco más de una década, la TPB se ha venido utilizando para explicar la formación de las intenciones reproductivas (Billari et al., 2009; Dommermuth et al., 2011; Ciritel et al., 2019), y ha sido adoptada como marco teórico de referencia en el proyecto internacional Repro, que aborda las decisiones reproductivas desde una perspectiva macro-micro (Philipov et al., 2015).

Un componente central de la teoría es la «intención de tener un hijo», es decir, la decisión razonada de intentar tener un hijo (Klobas y Ajzen, 2015), que se diferencia de los deseos reproductivos — categoría altamente discutida en la literatura (Miller, 2011b). En la TPB esta intención se explicaría a partir de tres antecedentes directos: actitudes, normas y percepción de control sobre circunstancias externas que puedan constituir barreras o limitaciones para la decisión en cuestión. Siguiendo a Liefbroer et al. (2015), y tomando como 
Figura 1. Antecedentes de la intención de tener un hijo en un período de tiempo determinado, de acuerdo con el modelo de la Teoría del Comportamiento Planificado (TPB).

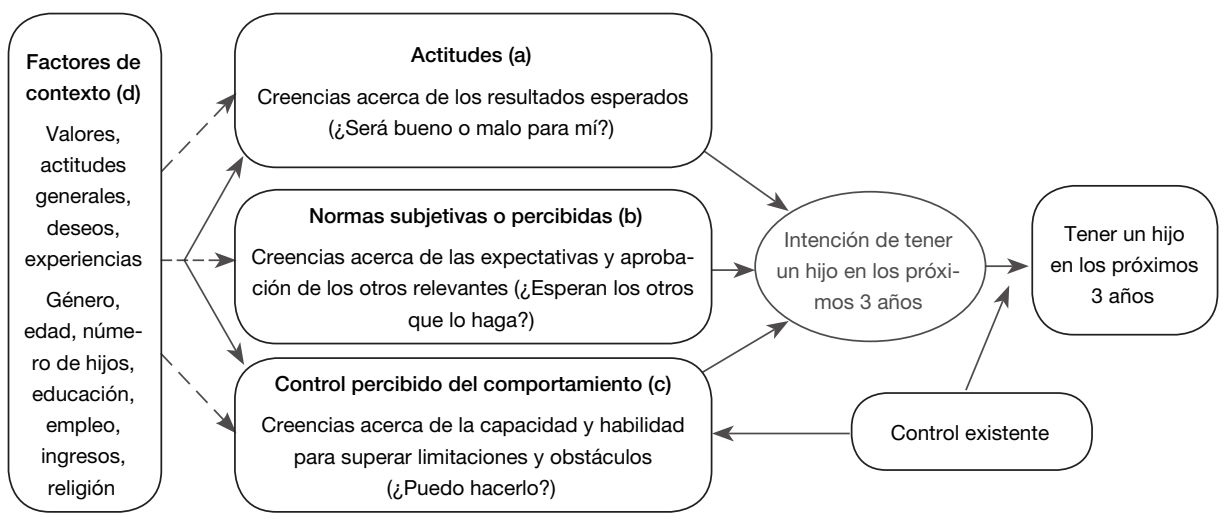

Fuente: tomado de Liefbroer et al. (2015: 8), traducción propia.

referencia la figura 1, presentamos una síntesis de los elementos centrales de este modelo teórico:

a) Las actitudes se refieren a la evaluación interna acerca del impacto positivo o negativo que traerá, previsiblemente, la realización de un comportamiento o el alcance de un objetivo. La actitud hacia la tenencia de un hijo en un momento temporal determinado se configuraría a partir de la evaluación razonada de los costes y beneficios percibidos que se asocian a la llegada del bebé (Dommermuth et al., 2011).

b) La TPB también considera la influencia de elementos normativos sobre la configuración de la intención reproductiva, con el planteamiento de que las normas subjetivas o percibidas constituyen un antecedente directo de la intención de tener un hijo en un marco temporal determinado. El modelo se ha centrado fundamentalmente en la percepción de aprobación o desaprobación de los otros significantes (familia, amigos, personas cercanas).

c) Respecto al control percibido del comportamiento, se trata de la percepción acerca de la capacidad de afrontar las circunstancias que pueden facilitar o dificultar la tenencia de un hijo. Aunque se trata de una de las dimensiones más discutidas del modelo (Ajzen, 2002), estudios como el de Dommermuth et al. (2011) apuntan que el control percibido puede actuar como indicador fiable de las limitaciones y las barreras existentes para la tenencia de hijos («control existente», en la figura 1).

d) El modelo también considera la influencia de factores de contexto: se trata de características personales que influirían sobre los antecedentes inmediatos. Se incluyen variables objetivas como el género, la edad, el número de 
hijos, el nivel educativo, el nivel de ingresos, el estatus laboral, la religión y otras de tipo subjetivo, como valores, actitudes y preferencias generales.

De acuerdo con el modelo, los tres antecedentes directos de la intención estarían interrelacionados entre sí, y la decisión final dependería del peso relativo que se les atribuya en un contexto determinado (Liefbroer et al., 2015).

Sabemos que la aplicación de la TPB al estudio de las intenciones de fecundidad requiere aún más trabajo metodológico y teórico (Liefbroer et al., 2015), y que ha recibido críticas (Bachrach y Morgan, 2011; Morgan y Bachrach, 2011). Pero la utilidad del modelo para la investigación en fecundidad ha sido reconocida por otros autores (Liefbroer, 2011), quienes valoran el potencial de la TPB para establecer conexiones entre el nivel social y el individual. Al tratarse de un modelo altamente inclusivo y abarcante, permite relacionar una amplia variedad de factores y aportaciones provenientes de distintos marcos teóricos, con el acento puesto en la percepción y la valoración que las personas mantienen de estos factores.

En cuanto a los costes o los efectos negativos percibidos de la tenencia de un hijo, el modelo permitiría integrar algunas aportaciones en torno al coste de oportunidad que representan los hijos para las mujeres madres trabajadoras, relacionadas con la literatura sobre penalización por maternidad. Desde una perspectiva sociológica, se ha empezado a abordar la discriminación de las mujeres que son madres en los procesos de selección y contratación por parte del empleador. Se dispone de evidencia según la cual las mujeres que son madres gozarían de una menor valoración en los procesos de selección (Correll et al., 2007), a la vez que tendrían una menor probabilidad de recibir una llamada para una entrevista de trabajo que aquellos hombres con hijos cuyas características en el currículum serían comparables (35,9 \% inferior) (González et al., 2019). Asimismo, existe una evidencia que apunta que el aplazamiento en la tenencia del primer hijo contribuiría a reducir el impacto salarial negativo de la llegada de los hijos sobre las madres trabajadoras de nivel educativo alto (Miller, 2011a; Doren, 2019).

Para España, sabemos que el aplazamiento de la primera fecundidad habría empezado entre los hombres y mujeres con mayor nivel educativo (Vidal-Coso y Miret-Gamundi, 2017) y mayor potencial de ingresos, si bien el retraso se habría generalizado posteriormente para todos los estratos sociales (Castro Martín et al., 2018). Esto nos lleva a pensar en la probabilidad de que el aplazamiento del primer hijo esté constituyendo una estrategia utilizada a fin de minimizar el impacto negativo de su llegada para el ámbito laboral remunerado de la mujer. No solo los hijos tendrían un efecto negativo sobre el trabajo remunerado, sino que este ámbito también afectaría las decisiones en torno a la fecundidad y al tempo de los nacimientos. Si una de estas decisiones es la referente al aplazamiento en la tenencia de los hijos, algunos estudios han apuntado que la explicación principal de dicho aplazamiento es la planificación de la carrera profesional de la mujer (Gustafsson, 2001; 2005). 
Pero la percepción de costes también puede estar abarcando otros ámbitos vitales, como el ocio y el tiempo libre, asociados a la extensión de la juventud. La literatura previa ya había señalado la necesidad de incluir este factor entre los determinantes micro de la fecundidad, y había destacado que uno de los elementos asociados a dicha extensión es el de un empleo del tiempo que favorece la socialización y las prácticas de ocio juvenil, lo cual contribuiría a disminuir el lugar disponible para el niño (Gauthier y Charbonneau, 2002). Billari (2004) había apuntado que el retraso en la transición a la edad adulta en los países del sur de Europa, como España, implicaba un retraso en la edad de salida del hogar de origen, en la formación de pareja y de la tenencia de los hijos propios.

La percepción de costes en estos ámbitos vitales podría estar relacionada con la elevada valoración que se atribuye a la autonomía personal, en línea con la Teoría de la Segunda Transición Demográfica (Lesthaeghe, 1983; Surkyn y Lesthaeghe, 2004; Lesthaeghe, 2010). Desde esta, se acentúa el ascenso de la autonomía individual y de las necesidades posmaterialistas de autorrealización personal en las sociedades avanzadas, como factor que habría impulsado nuevos comportamientos y formas de organización familiar, entre los que destaca el aplazamiento de la tenencia de los hijos.

En cuanto al papel de las normas sociales percibidas, Billari et al. (2009) y Dommermuth et al. (2011) habían encontrado que la presión social normativa procedente de los otros significantes - como la familia y el círculo cercano de amigos - tenía un impacto importante sobre las intenciones reproductivas en general, y sobre el tempo de las mismas. Para Liefbroer y Billari (2010), las normas sociales seguirían teniendo influencia sobre los comportamientos relacionados con la fecundidad, y señalarían la existencia de normas de edad. Ciritel et al. (2019) encontraban que en un contexto de baja fecundidad como Rumanía la presión social normativa era el factor más importante que afectaba las decisiones reproductivas de las personas sin hijos.

En cuanto a la percepción de control sobre factores que limitan o dificultan la decisión reproductiva, un buen número de estudios apuntan la estabilidad laboral y económica como condiciones fundamentales para la tenencia de los hijos. Se dispone de evidencia acerca del efecto del desempleo y la inestabilidad de las condiciones económicas en el aplazamiento de la tenencia de los hijos (Adsera, 2011; Kreyenfeld et al., 2012), y de la existencia de una relación negativa entre la incertidumbre económica y la intención de tener el primer hijo, especialmente para los hombres (Fahlén y Oláh, 2018). Para España, Rica e Iza (2005) habían encontrado que aquellas mujeres sin hijos y con contratos temporales aplazaban la entrada en la maternidad a la espera de obtener contratos fijos. Matysiak et al. (2020) destacan una asociación entre el deterioro de las condiciones económicas durante la Gran Recesión - y unido a la percepción de una mayor incertidumbre- y el declive de la fecundidad, especialmente en el sur de Europa.

El modelo TPB reconoce la importancia del contexto en el que se configuran las intenciones reproductivas de las personas (Klobas y Ajzen, 2015). En la 
investigación comparada que estos autores llevaron a cabo, señalaban la necesidad de definir creencias y opiniones relevantes para cada contexto y subrayaban que aún quedaba margen considerable para esclarecer cuáles son las que mayor importancia tienen ante la decisión de tener un hijo en contextos específicos.

Ante el número relativamente limitado de estudios que han abordado aspectos relacionados con las intenciones reproductivas - fundamentalmente, las referentes al aplazamiento-, desde una perspectiva micro para el caso español (Sampedro et al., 2002; Delgado et al., 2009; Alvarez, 2018; Bueno y Brinton, 2019; Lebano y Jamieson, 2020), y, hasta donde sabemos, ante la ausencia total de estudios que lo hayan hecho siguiendo el modelo teórico $\mathrm{TPB}$, esta investigación busca efectuar una aportación científica y social relevante de cara a comprender las percepciones y las valoraciones que estarían configurando el aplazamiento de la tenencia de los hijos.

\section{Preguntas de investigación e hipótesis}

Tomando como marco teórico de referencia la TPB, este artículo indaga cuáles son las percepciones y las valoraciones más relevantes que estarían influyendo en el retraso de la tenencia del primer hijo entre las personas de 25 a 45 años residentes en la Comunidad de Madrid. En respuesta a la necesidad de esclarecer las creencias y las opiniones relevantes en materia de intenciones reproductivas para un contexto específico (Klobas y Ajzen, 2015) como el español, se ha optado por una metodología cualitativa: entrevistas en profundidad semiestructuradas. Esto nos ha llevado a simplificar algunos de los elementos del modelo teórico, fundamentalmente, el referente al control percibido del comportamiento, que - siguiendo la estrategia de estudios anteriores, como el de Klobas y Ajzen (2015) — abordaremos en términos de las circunstancias percibidas de las que se hace depender el aplazamiento en la tenencia de los hijos.

A fin de contrastar si en el discurso de los entrevistados emergen aspectos relacionados con las tres dimensiones centrales de la TPB, y cómo influirían algunos de los factores de contexto sobre los tres antecedentes principales, se buscará responder a dos preguntas específicas: [P1] ¿Inciden la percepción de efectos negativos, de normas sociales y la dependencia de circunstancias externas sobre la intención de aplazar la tenencia del primer hijo? [P2] ¿Incide la valoración personal que se atribuye al trabajo remunerado y a un estilo de vida autónomo sobre las actitudes favorables al aplazamiento de la tenencia del primer hijo?

Para abordar estas preguntas de investigación, y de acuerdo con en el marco teórico planteado, se proponen una serie de hipótesis según un modelo simplificado y adaptado de la TPB (figura 2).

\section{Diseño metodológico}

Para responder a las preguntas de investigación formuladas — de carácter explicativo y no meramente descriptivo-, se ha optado por una aproximación 
Figura 2. Modelo adaptado y simplificado de la TPB. Hipótesis referentes a los antecedentes directos y a algunos factores subjetivos de contexto que incidirían sobre la intención de aplazar la tenencia del primer hijo.

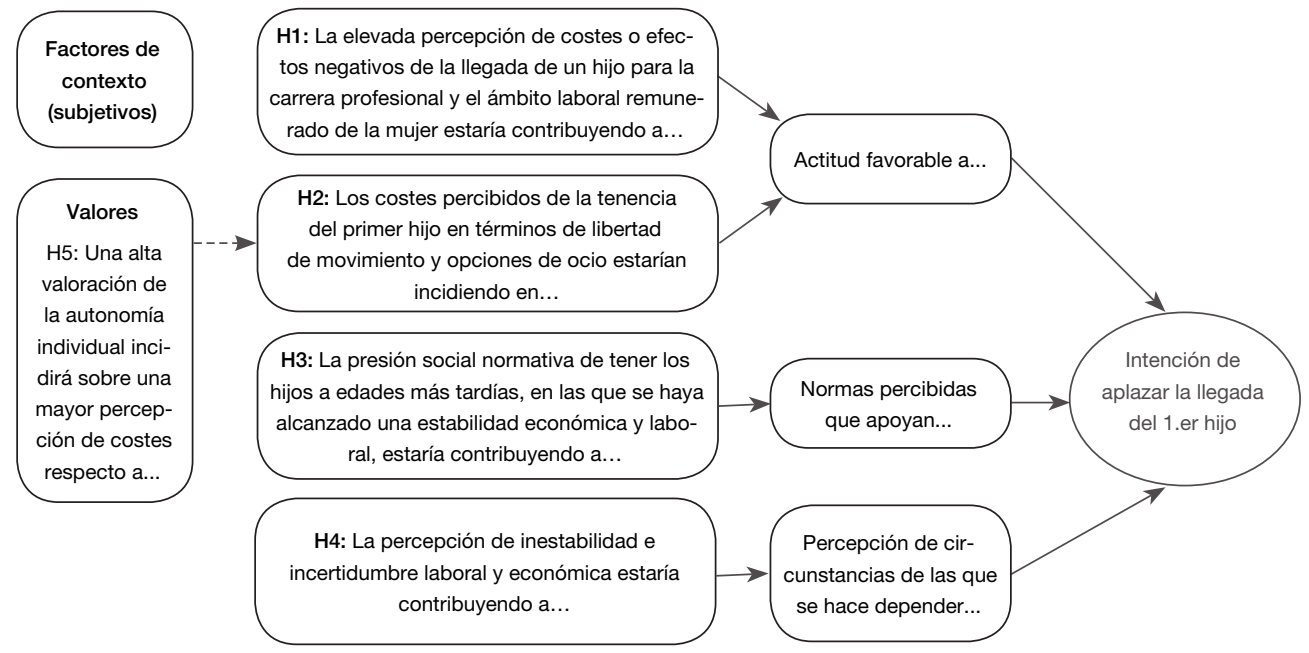

Fuente: elaboración propia, a partir del modelo teórico TPB recogido en Liefbroer et al. (2015: 8). Nota: H = hipótesis.

metodológica de carácter cualitativo, en línea con investigaciones recientes que han abordado aspectos relacionados con la fecundidad y las intenciones reproductivas (Bueno y Brinton, 2019; Lebano y Jamieson, 2020). Aunque los resultados de investigaciones de carácter cualitativo no pueden ser generalizados, su uso permite analizar cuestiones o comportamientos complejos - como el que aquí se aborda - mediante la obtención de un material rico y detallado (Valles Martínez, 2009).

Ante el abanico de métodos cualitativos disponibles, se optó por la realización de entrevistas en profundidad de carácter semiestructurado, por considerarlas más idóneas para abordar las opiniones y la valoración de los entrevistados en torno a los factores que estarían incidiendo en el aplazamiento de la tenencia del primer hijo. De acuerdo con la literatura, las entrevistas en profundidad permiten la emergencia de nuevas aportaciones no previstas, y que sean los propios entrevistados quienes describan su percepción. Dejar que los aspectos emerjan en el propio discurso de los entrevistados nos permitirá contribuir a una mejor comprensión de los factores que están incidiendo en el retraso de las intenciones reproductivas.

Para el presente estudio, se llevaron a cabo 16 entrevistas en profundidad, ${ }^{2}$ tomando como referencia al universo de hombres y mujeres entre 25 y 45

2. Las entrevistas se han realizado en el marco de un proyecto sobre la relación entre familia y trabajo que combina metodología cuantitativa y cualitativa, y cuyos primeros resultados se recogen en López López y González Hincapié (2017). 
años de edad residentes en la Comunidad de Madrid. Para la selección de la muestra, en línea con la propuesta de Valles (2009), se optó por un muestreo cualitativo a través de la elaboración de casilleros tipológicos, según tres variables: (i) grandes grupos de edad: entre 25 y 34 años, y entre 35 y 44 años; (ii) tipo de convivencia y tenencia o no de hijos: solteros, parejas sin hijos, parejas con hijos; (iii) entrevista individual (hombres y mujeres) o pareada.

El rango de edad escogido responde al hecho de que más del $95 \%$ de los nacimientos en España tienen lugar de madres en esa franja etaria (INE, 2019a). Cerca del $70 \%$ de los casos son de personas o parejas sin hijos o con un hijo: disponer de casos sin hijos nos permitía abordar las intenciones de aplazamiento prospectivo de la tenencia del primer hijo, mientras que contar con casos de personas con un hijo posibilitaba indagar las razones del aplazamiento en su llegada, en caso de que este se hubiese producido. El $30 \%$ restante de casos de personas o parejas con dos hijos o más nos permitía complementar las percepciones respecto a la valoración de las mujeres madres trabajadoras en el ámbito laboral remunerado.

La decisión de incluir a hombres en las entrevistas pareadas e individuales responde a una necesidad planteada por la literatura: dado el carácter tan limitado de los estudios que abordan cuestiones relativas a la fecundidad incorporando a hombres, la comprensión de las decisiones en este ámbito se beneficiaría de incluir tanto a hombres como a mujeres (Balbo et al., 2013). La decisión de realizar un mayor número de entrevistas individuales (11) que a parejas (5) se debe a que en temas tan personales y delicados como los abordados en las conversaciones hemos priorizado las entrevistas individuales, con el objetivo de facilitar mayor apertura y sinceridad por parte de los entrevistados. Al mismo tiempo, no queríamos dejar de contar con un cierto número de entrevistas a parejas, siguiendo otra recomendación de Balbo et al. (2013), quienes señalan que abordar estas cuestiones como decisiones conjuntas, en las que intervienen los dos miembros de la pareja, sería de un gran valor para el avance de la investigación en este campo.

En las 16 entrevistas en profundidad realizadas (11 individuales y 5 a parejas), participaron un total de 21 personas: 13 mujeres y 8 hombres (ver tabla 1 para una descripción de los casos). De las 21 personas entrevistadas, el $52 \%$ tenía estudios superiores (universitarios), y el 28,5 \% había alcanzado un nivel de estudios medios (bachillerato o formación profesional), lo cual nos permite señalar que estamos mayoritariamente ante una muestra de clase media.

A través de informantes clave se identificaron múltiples puntos de inicio independiente para el reclutamiento de las personas y parejas a entrevistar. Las entrevistas se realizaron siguiendo un guión temático. Tuvieron una duración aproximada de una hora, se llevaron a cabo entre abril y mayo de 2017 y fueron grabadas para permitir el posterior tratamiento y análisis de la información. Tras su realización, se llevó a cabo un estudio exploratorio y cualitativo de las mismas, por categorización de temas relevantes.

Al haber incluido tres categorías para el diseño muestral cualitativo, la restricción del número de entrevistas a 16 puede ser vista como una limitación. 
Tabla 1. Características sociodemográficas y situación laboral de las personas y parejas entrevistadas.

\begin{tabular}{|c|c|c|c|c|c|c|c|}
\hline Entrevista & Nombre ficticio & Sexo & Edad & $\begin{array}{l}\text { Estado civil y } \\
\text { situación de } \\
\text { convivencia }\end{array}$ & Hijos & $\begin{array}{l}\text { Nivel de } \\
\text { estudios }\end{array}$ & Situación laboral \\
\hline $\begin{array}{l}\text { EP1 } \\
\text { (individual) }\end{array}$ & Almudena & Mujer & $35-40$ & Casada & 2 & Superiores & $\begin{array}{l}\text { Trabaja a jornada } \\
\text { completa }\end{array}$ \\
\hline $\begin{array}{l}\text { EP2 } \\
\text { (individual) }\end{array}$ & María & Mujer & $25-30$ & $\begin{array}{l}\text { Soltera, con pareja, } \\
\text { no cohabitan }\end{array}$ & 0 & Superiores & $\begin{array}{l}\text { De prácticas y } \\
\text { opositando }\end{array}$ \\
\hline $\begin{array}{l}\text { EP3 } \\
\text { (pareja) }\end{array}$ & Sandra y Pedro & Pareja & $\begin{array}{l}\text { Ambos: } \\
25-30\end{array}$ & $\begin{array}{l}\text { Solteros en pareja } \\
\text { cohabitando }\end{array}$ & 0 & $\begin{array}{l}\text { Superiores } \\
\text { (ambos) }\end{array}$ & $\begin{array}{l}\text { Ambos trabajan } \\
\text { a jornada completa }\end{array}$ \\
\hline $\begin{array}{l}\text { EP4 } \\
\text { (pareja) }\end{array}$ & Cristina y Martín & Pareja & $\begin{array}{l}\text { Ella: } 30-35 \\
\text { Él: } 25-30\end{array}$ & Casados & 1 & $\begin{array}{l}\text { Superiores } \\
\text { (ambos) }\end{array}$ & $\begin{array}{l}\text { Ambos trabajan a } \\
\text { jornada completa }\end{array}$ \\
\hline $\begin{array}{l}\text { EP5 } \\
\text { (individual) }\end{array}$ & Alberto & Hombre & $35-40$ & Soltero & 0 & Superiores & $\begin{array}{l}\text { Trabaja a jornada } \\
\text { completa }\end{array}$ \\
\hline $\begin{array}{l}\text { EP6 } \\
\text { (individual) }\end{array}$ & Carmen & Mujer & $30-35$ & Casada & 0 & $\begin{array}{l}\text { Medios } \\
\text { (bachillerato) }\end{array}$ & $\begin{array}{l}\text { Trabaja a jornada } \\
\text { completa y cursa } \\
\text { estudios universitarios }\end{array}$ \\
\hline $\begin{array}{l}\text { EP7 } \\
\text { (individual) }\end{array}$ & Julia & Mujer & $30-35$ & $\begin{array}{l}\text { Solteros en pareja } \\
\text { cohabitando }\end{array}$ & 1 & $\begin{array}{l}\text { Medios } \\
\text { (bachillerato) }\end{array}$ & $\begin{array}{l}\text { Trabaja a jornada } \\
\text { parcial }\end{array}$ \\
\hline $\begin{array}{l}\text { EP8 } \\
\text { (individual) }\end{array}$ & Pablo & Hombre & $30-35$ & Soltero & 0 & $\begin{array}{l}\text { Medios } \\
\text { (bachillerato) }\end{array}$ & Opositando \\
\hline $\begin{array}{l}\text { EP9 } \\
\text { (individual) }\end{array}$ & Sara & Mujer & $35-40$ & Casada & $>2$ & Superiores & $\begin{array}{l}\text { Trabaja a jornada } \\
\text { completa }\end{array}$ \\
\hline $\begin{array}{l}\text { EP10 } \\
\text { (individual) }\end{array}$ & David & Hombre & $40-45$ & Casado & 2 & Superiores & $\begin{array}{l}\text { Trabaja a jornada } \\
\text { completa }\end{array}$ \\
\hline $\begin{array}{l}\text { EP11 } \\
\text { (individual) }\end{array}$ & María José & Mujer & $35-40$ & Casada & 0 & $\begin{array}{l}\text { Medios } \\
\text { (formación } \\
\text { profesional) }\end{array}$ & $\begin{array}{l}\text { Trabaja a jornada } \\
\text { parcial }\end{array}$ \\
\hline $\begin{array}{l}\text { EP12 } \\
\text { (individual) }\end{array}$ & Alba & Mujer & $35-40$ & $\begin{array}{l}\text { Soltera cohabitando } \\
\text { ocasionalmente }\end{array}$ & 0 & Superiores & $\begin{array}{l}\text { Trabaja a } \\
\text { jornada completa }\end{array}$ \\
\hline $\begin{array}{l}\text { EP13 } \\
\text { (pareja) }\end{array}$ & Silvia y Javier & Pareja & $\begin{array}{l}\text { Ambos: } \\
40-45\end{array}$ & Casados & 1 & $\begin{array}{l}\text { Superiores } \\
\text { y medios } \\
\text { (bachillerato) }\end{array}$ & $\begin{array}{l}\text { Él trabaja a jornada } \\
\text { completa; ella no } \\
\text { tiene actualmente un } \\
\text { trabajo remunerado }\end{array}$ \\
\hline $\begin{array}{l}\text { EP14 } \\
\text { (pareja) }\end{array}$ & Gema yAntonio & Pareja & $\begin{array}{l}\text { Ella: } 40-45 \\
\text { Él: } 35-40\end{array}$ & Casados & 1 & $\begin{array}{l}\text { Básicos } \\
\text { (secundaria) }\end{array}$ & $\begin{array}{l}\text { Él trabaja a jornada } \\
\text { completa; ella trabaja } \\
\text { a jornada parcial }\end{array}$ \\
\hline $\begin{array}{l}\text { EP15 } \\
\text { (pareja) }\end{array}$ & Isabel y Manuel & Pareja & $\begin{array}{l}\text { Ambos: } \\
30-35\end{array}$ & $\begin{array}{l}\text { Solteros } \\
\text { cohabitando }\end{array}$ & 2 & $\begin{array}{l}\text { Medios } \\
\text { (bachillerato) } \\
\text { y básicos } \\
\text { (secundaria) }\end{array}$ & $\begin{array}{l}\text { Él trabaja a jornada } \\
\text { completa; ella trabaja } \\
\text { a jornada parcial }\end{array}$ \\
\hline $\begin{array}{l}\text { EP16 } \\
\text { (individual) }\end{array}$ & Marta & Mujer & $40-45$ & Soltera & $>2$ & $\begin{array}{l}\text { Básicos } \\
\text { (secundaria) }\end{array}$ & $\begin{array}{l}\text { Trabaja a jornada } \\
\text { completa }\end{array}$ \\
\hline
\end{tabular}

Fuente: elaboración propia. 
Las restricciones presupuestarias para llevar a cabo un número mayor de entrevistas - lo cual habría sido deseable — no nos impidieron seguir adelante, debido, fundamentalmente, al carácter exploratorio de esta investigación, emprendida en un momento en que la comunidad científica contaba con poquísimos datos sobre las decisiones reproductivas en España, y más precisamente en la Comunidad de Madrid. El reconocimiento de esta limitación nos llevará a ser cuidadosos a la hora de extraer conclusiones, sobre todo, en aquellas categorías para las que hemos contado con un número de casos más restringido.

El análisis de contenido de las entrevistas se acompaña con extractos de las mismas, indicando al final de cada una de las citas extraídas el nombre ficticio de las personas y el número de la entrevista.

\section{Resultados}

\subsection{Percepción de costes y aplazamiento del primer hijo}

\subsection{1. Ámbito laboral remunerado}

En las declaraciones de los entrevistados emerge como opinión generalizada la percepción de una valoración negativa de la tenencia de hijos en el ámbito laboral para el caso de las mujeres. Esta percepción encuentra sus primeras manifestaciones con relación al embarazo:

En el trabajo no es un buen momento para quedarte embarazada porque ya sabes cómo está de mal visto el tema de las embarazadas en las empresas, desde la pequeña empresa hasta en la grande. Yo llevo con mi jefa siete años y valemos hasta que podemos trabajar... Tu jefe se entera que estás embarazada y parece que tienes la fiebre amarilla, qué vamos a hacer, otra vez mala, está de baja. (Carmen [EPG])

...motivos de trabajo, que no puedas permitirte llegar a un trabajo diciendo que estás embarazada, que eso ocurre; que no puedas permitirte una baja. [...] Yo creo que todo eso pasa más de lo que debería pasar. (Alba [EP12])

Una mujer embarazada es una mujer que ya no puede hacer nada. Es un estorbo [...]. Eres un lastre (ella). O si entras de nuevas y a los tres meses te quedas embarazada te pueden echar (él). Y si eres soltera no te cogen en el trabajo, porque te puedes quedar embarazada y es un problema. Y eso lo hemos vivido hace muy poquito con mi hermana pequeña. Quería entrar a otro supermercado, pero como es soltera, por si acaso se echa novio y se queda embarazada, no te cojo. (Gema y Antonio [EP14])

Esta percepción de una valoración negativa del embarazo parece concretarse en una devaluación de responsabilidades de las mujeres en los entornos laborales, que podría llegar incluso hasta el despido:

A la vuelta de la baja estás defenestrada, tengo una amiga que ha vuelto y el jefe le ha dicho que se busque algo. Gente de estudios superiores. Tengo otra amiga 
que trabaja de informática y le pasa lo mismo, se quedó embarazada, tuvo que hacer cambio de proyecto y la tuvieron en el limbo. (Almudena [EP1])

He visto casos de gente que cuando ha vuelto a su puesto de trabajo lo conservaba, pero tenía menos responsabilidades, como si lo hubieran devaluado. (Alberto [EP5])

A una amiga nuestra la han despedido por estar embarazada, o sea, en cuanto volvió de la baja, la despidieron y legalmente no podían. (Isabel [EP15])

La sensación de que se cuenta menos con la persona desde el momento en que se sabe que está embarazada se traduce en miedo a la devaluación, lo que lleva a algunas mujeres a desarrollar estrategias de ocultación de su situación en el entorno laboral:

Tengo amigas que se han quedado embarazadas y no han querido decirlo en el trabajo. No se lo querían decir al jefe porque si no las retiran de los proyectos. El ambiente es distinto con los compañeros. Al final, como desapareces, cuentas menos, como te vas a dar de baja, no cuentan contigo, y claro tú estás igual que antes, solo que después del trabajo sigues teniendo tu vida. (Almudena [EP1])

Subyace la idea de que las mujeres que han tenido hijos van a rendir menos en el ámbito laboral remunerado, con lo cual ellas se verían obligadas a demostrar que la llegada de un hijo no afecta para nada en su desempeño profesional:

[...] decides tener familia, y una mujer, en el mundo laboral, pues tienes hijos y dan por hecho que vas a rendir menos o vas a faltar más... (Cristina [EP4])

Mi amiga ha hecho todo lo posible para mantener sus horas de trabajo, para no bajar de horas, tanto de cara a que no la miren mal y también por su propia economía, cuando tienes un hijo tienes que demostrar que no afecta para nada a tu trabajo. (Julia [EP7])

Sin embargo, los propios entrevistados reconocen la existencia de diferencias relevantes en cuanto al signo de la valoración que se otorga al embarazo y a la llegada de los hijos, en función del sector - público o privado- de actividad. La valoración negativa de la llegada de los hijos, y de las medidas de conciliación a ella asociadas, parece ser más común en las empresas privadas que en el sector público:

Tú trabajas en la empresa privada y sabes que no, que por mucha conciliación no hay una cultura de que eso se valore y se aplauda y se proteja [...]. A la hora de la verdad, si tú dejas de trabajar un año para atender a un niño, o eres funcionaria o cuando vuelvas no tienes ninguna meta por delante, has perdido un año en un sistema supercompetitivo donde hay gente luchando por tener un trabajo, y tú te has ido un año, y se va a valorar de pena. (Alba [EP12]) 
Es que depende de tu situación, porque a mí en el trabajo me dan muchas facilidades. Pero también es porque es el sector público. Claro, nadie te pone malas caras, al contrario [...]. Pienso que en la empresa privada te ponen muchas más trabas, incluso siguen estando las mujeres con hijos con muchas más dificultades. O con hijos o en edad de tenerlos... Ya te contratan menos, si te quedas embarazada incluso sigue habiendo despidos. (Isabel [EP15])

El temor a las repercusiones negativas de la tenencia de hijos y el deseo de amortiguar al máximo los efectos negativos que previsiblemente recaerán sobre ellas estarían operando como factores de aplazamiento de la maternidad en algunos casos. Debido a que las mujeres perciben que su valoración en el ámbito laboral remunerado se ve afectada por la llegada de los hijos, algunas consideran necesario haber consolidado su situación profesional antes de la llegada del primer hijo:

Ahora esperas a más tarde a tener hijos, igual ya has hecho carrera en tu trabajo y no te has interrumpido por las bajas, porque quieras que no, te desplazan. (Almudena [EP1])

El trabajo no facilita..., la gente con el rollo de «este no es el momento» lo va retrasando, y en mi caso no era el momento, y suena atípico, pero uno tira para adelante como puede. (Julia [EP7])

Algunos hombres comparten la percepción de que el retraso en la edad de tenencia de los hijos estaría asociado a la necesidad que afrontan las mujeres de afianzarse primero en un puesto de trabajo:

Muchas mujeres no han podido o no han querido tener los hijos hasta un momento determinado, hasta no afianzar, no siendo directores, sino afianzarse en un puesto de trabajo, para que el empresario no considere que, si se queda embarazada, entonces no te contrato, o te dé de baja... Sigue pasando. (Javier [EP13])

Algunas, como Sandra, hacen cálculos acerca del tempo para la tenencia de su primer hijo con relación a su situación laboral. Lo que más pesa en su decisión es la percepción de que tenerlos antes traería consigo efectos negativos de cara al acceso a puestos de responsabilidad en la empresa:

O por lo menos en ámbito mujeres, yo veo que en cuanto tengas un hijo, cuanto antes lo tengas antes te van a echar para atrás, en puestos de responsabilidad (...). Creo que en cuanto saben que tienes un hijo, ya no te toman tan en cuenta como a un hombre para un puesto de responsabilidad, con lo cual sí que creo que es algo que te echa para atrás. (Sandra [EP3])

Ella misma relata cómo ha ido retrasando la fecha para tener su primer hijo, debido — entre otros factores — al deseo de progresar profesionalmente: 
Conforme han ido pasando los años, he ido retrasando la fecha, a mí siempre me han gustado los niños y yo de pequeña pensaba que más bien 30 , que era una buena edad. Ahora, según se van acercando los 30, veo que todavía me quedan muchas cosas que quiero hacer, quiero progresar en mi vida, o que quiero tener antes de tener niños, por lo cual sí que me planteo unos 35. [...] Yo es que con 30 ya no sé si quiero tener un hijo, ya me voy más a los 35 quizás... Porque yo creo que, por trabajo, a lo mejor quiera crecer un poco más... (Sandra [EP3])

Un factor relacionado con el ámbito laboral que emerge con frecuencia en los discursos con relación a la intención de aplazamiento es el deseo de realización en el ámbito laboral por parte de las mujeres:

Hoy en día la mujer es otra cosa, ya no es quedarme en casa a cuidar a los niños, hoy en día es una carrera, y te metes en un proyecto determinado y quieres seguir creciendo profesionalmente y lo vas atrasando, atrasando; sí, sí, yo quiero ser madre, pero es la pescadilla que se muerde la cola. Y hoy como ves a tanta gente y sabes que puedes tener hijos a los 40 años, dices, tengo tiempo todavía y lo vas atrasando... (ella). Se va acortando la edad para tener niños, y si antes hubieras tenido tres ahora solo llegas a uno (él). (Silvia y Javier [EP13])

Tanto Sandra como Isabel consideran que se ha producido un cambio en las prioridades vitales de las mujeres, con un ascenso de la valoración que se atribuye al trabajo remunerado y a la realización profesional, frente al valor que se atribuye a la familia y a los hijos:

Yo creo que han cambiado un poco las prioridades. A lo mejor se da más prioridad a tener un trabajo, y estar... no tener que luego depender de cuidar a un hijo o tener que... [...] preocuparse de otras muchas cosas que implica una persona nueva en tu vida, que hasta los 18 o más va a ser dependiente tuya, sino que tener un poco más de libertad [...]. (Sandra [EP3])

Porque ahora la motivación principal en la vida no es tener hijos. Es realizarte profesionalmente, $\mathrm{mmm}$... viajar mucho, y con hijos ya no puedes hacerlo tanto. (Isabel [EP15])

\subsubsection{Ocio y tiempo libre}

Otro de los elementos más valorados que emerge con fuerza en el discurso de los entrevistados - especialmente entre los más jóvenes que aún no tienen hijos- es el relativo al ocio y al tiempo libre. Frente a esto, los hijos son vistos como una carga, solo asumible una vez que se haya disfrutado de las múltiples opciones de ocio y de libertad de movimiento disponibles:

Una amiga me dice que no quiere hijos, que no quiere estar atada a algo [...], ella quiere viajar cuando quiera viajar, a ella le gusta salir y tener vida social y sabe que el hecho de tener un niño va a ser una limitación. [...] Para mi amiga 
no es un problema económico, ella prefiere su libertad y poder hacer lo que le da la gana y no atarse. (Cristina [EP4])

La incompatibilidad percibida entre la tenencia de hijos y la tan valorada libertad de movimiento implica que los hijos se vean como una "atadura» que limita, o incluso imposibilita poder seguir con un estilo de vida muy autónomo, en el que no se tiene que asumir la responsabilidad de otra persona. Entonces, el primer hijo se posterga a un momento vital en el que ya se hayan agotado las posibilidades que ofrece esa libertad y los patrones de ocio a ella asociados:

Pienso que con hijos me cambiaría mucho la vida, y a ella también, y quizás soy demasiado egoísta y prefiero mi dinero y el de mi pareja utilizarlo para viajar y no estar atado. Yo sí que veo que es una atadura lo de los hijos ahora mismo, tiene que ser bonito pero me privaría de hacer mil cosas y creo que todavía soy joven para seguir haciendo cosas que no he hecho, sitios a los que quiero ir, planes que seguramente teniendo un hijo [...] estaría bastante limitado y estresado. (Alberto [EP5])

Pablo, por su parte, reconoce que actualmente los jóvenes están acostumbrados a un estilo de vida con una amplísima libertad de movimiento, a la que no se está dispuesto a renunciar para tener un hijo:

No puedes irte de viaje con un recién nacido, no puedes irte de fiesta con un niño, no puedes ir con un niño de 3 años al cine. (Pablo [EP8])

El coste percibido de la llegada de un hijo para la libertad de movimiento y los patrones de ocio, como un factor directamente asociado al retraso de la paternidad, no emerge solo en el discurso de algunos de los hombres entrevistados, sino que también está presente en el de las mujeres. Así lo relata Sandra, para quien sería ideal poder tener su primer hijo más allá de los 40 años, una edad en la que no solo se ha alcanzado mayor estabilidad, sino que "ya te has movido todo lo que querías moverte»:

A lo mejor, si biológicamente o físicamente hablando, pudieses tenerlos (hijos) a los 40 , que tienes..., o a los 45 , que tienes más estabilidad, que ya has vivido bastante, que ya te has movido todo lo que a lo mejor quieres moverte, etcétera, pues a lo mejor sí que la gente se lo pensaría [...]. Yo creo que los 30 ya se nos quedan como muy justos para empezar a pensar en tener hijos, se nos hace un poco cuesta arriba, a mí por lo menos... (Sandra [EP3])

La enorme diversificación de opciones de ocio y de movimiento estaría incidiendo en la percepción de tener todavía mucho que aprovechar antes de dar el paso a la decisión de tener el primer hijo:

Yo creo que también ha influido el acceso al ocio. Antes, viajar no era tan fácil, no había tantos medios o no estaba tan al alcance de todos, ahora moverte de aquí a la India pues es bastante fácil, hay muchos viajes, muchos vuelos, 
muchas opciones culturales, de moverte, de actividades de todo tipo, con lo cual yo creo que también es eso, te llama y quieres aprovecharlo (ella). [...] No solo el hecho de viajar, sino también la experiencia de poder salir y no estar atado a nada. [...] Ir con familia... es mucho más complicado (él). (Sandra y Pedro [EP3])

[...] nos hemos hecho más cómodos, más independientes, nos llenan la vida muchas cosas, no queremos renunciar a viajar, [...] y luego sobre todo que estamos tan estimulados, tenemos la posibilidad de estimularnos tanto con muchas cosas. (Alba [EP12])

La decisión de tener el primer hijo se asocia a un cambio de etapa en el ciclo vital, ya que marca el fin de la juventud y el paso a la edad adulta:

Cuando ya quieres asentarte y sentar la cabeza y tener otros planes, es cuando piensas que sería importante tener hijos. (Sandra [EP3])

Porque ahora la motivación principal en la vida no es tener hijos... No es tener una familia y tener hijos... Es divertirte, conocer, hacer cosas nuevas, tu ocio, creo que se pone en primer lugar. Y luego, ya cuando ya te haces mayor, te dices: o los tengo o no voy a poder tenerlos, y entonces ya... (Isabel [EP15])

Los hijos constituyen una responsabilidad, y el miedo a asumirla emerge como uno de los factores que estarían influyendo sobre el retraso en las intenciones reproductivas: uno es responsabilidad; dos, pérdida de ocio, que yo creo que son cosas que ahora mismo con esta edad sí que pretendemos. (Pedro [EP3])

Claro que influye el miedo a la responsabilidad de tener hijos, es que no puedes devolver al niño, te tienes que quedar con él toda la vida. (Isabel [EP15])

[... ten en cuenta que cuando ya tienes un niño es ya para toda la vida y depende de ti. Yo creo que es eso, miedo, sí, es un miedo, el responsabilizarte de algo. (María José [EP11])

\subsection{Normas sociales percibidas y aplazamiento del primer hijo}

Frente a la posible presión social normativa ejercida por el entorno cercano — familia, amigos y grupos de pares — sobre las decisiones reproductivas, el discurso de buena parte de los entrevistados coincide en señalar la primacía de la autonomía personal en este tipo de decisiones. Se percibe que las presiones normativas en este ámbito se habrían relajado, en comparación con el pasado:

Puedes decidir tener o no tener hijos, por suerte es una decisión y no es algo que viene obligatorio. [...] Antes estaba mal visto que una mujer, que un matrimonio, no tuviera hijos. Era algo raro. Ahora cada vez está más asumido en esta sociedad. (María [EP2]) 
También tienen menos peso los padres de origen, antes eran los que más solían... pues esa idea de la continuidad familiar y tal. También ellos entienden que hay otras maneras de verlo, que hay menos presión en general, hay más gente en circunstancias similares... (Alba [EP12])

La menor presión social percibida también estaría influyendo en las decisiones reproductivas referentes al tempo de tenencia de los hijos. Así lo señala Julia, quien considera que a diferencia del pasado, donde la tenencia de hijos era en cierto modo regulada normativamente por la sociedad, "ahora se puede elegir y retrasar»:

Ahora se puede decidir y hay libertad. Yo no creo que haya gente de la generación de nuestros padres o las anteriores que podía decir: "Yo quiero ser libre y yo paso». Te tocaba ser mujer y tener hijos y crear tu familia. No me creo que toda la gente antes quisiera tener familia y ahora estemos todos egoístas. Ahora se puede elegir y retrasar, puedes tener tu época egoísta y luego tu época de ahora no. O ahora no me importa dejar de serlo. (Julia [EP7])

La presión social normativa del entorno de amigos podría operarse de modo tácito, y no necesariamente directo. Tanto Pedro como Sandra reconocen que, aunque actualmente su círculo de amigos no represente una presión o una influencia en este sentido, es probable que sí lo sea en un futuro:

Por parte de mis amigos, no, porque a casi ninguno de mis amigos les veo teniendo hijos, y no creo que forme parte de sus planes. Y familiarmente, la verdad es que por lo menos mis padres son bastante tranquilos en ese tema, no me presionan para nada. [...] (ella). Igual te plantas en x años, y empiezan todos tus círculos a tener hijos, y dices... que esto ya... (él). Que ya va siendo hora (ella). Que me hago viejo, que todos aquí están teniendo hijos menos yo... Igual eso puede presionarte. Pero yo creo que a día de hoy diría que no presiona, o sea, no me va a animar a tener hijos (él). (Sandra y Pedro [EP3])

Aunque la presión por emulación del comportamiento de los pares tendría cierta influencia en las decisiones reproductivas, no se trata de una regla general aplicable a todos los casos. La elevada valoración de la autonomía individual, que estaría incidiendo en el estilo de toma de decisiones reproductivas, y la pérdida de relevancia de la presión normativa a este respecto se ven reflejadas en el estilo de vida de aquellos que, como Alberto, priorizan su independencia y no perciben ninguna señal normativa del patrón de comportamiento de su círculo de amigos, o de los deseos de sus padres. A él no le preocupa llegar a los 40 años sin hijos:

Te lo digo porque sí que me he dado cuenta de que mucha gente de mi entorno, sobre todo amigos de la facultad, del colegio, obviamente, hemos ido creciendo, pues la mayoría están ya casados, con hijos, con hipotecas... La típica vida que quieren mis padres, pero que a lo mejor yo, que soy un poco más atípico, pues no es lo que a mí me hace feliz. Tengo mi apartamento, vivo 
solo, vengo a trabajar andando, tengo mi coche, estoy de alquiler, pero no estoy pagando una hipoteca, no pienso en tener hijos, no me preocupa... Ya te digo, tengo 37 y no me preocupa llegar a los 40 y no tener hijos. (Alberto [EP5])

En las declaraciones de otros entrevistados emerge la presencia de algunas presiones sociales normativas relacionadas con la edad de tenencia de los hijos. Parece que, por un lado, la edad mínima para la tenencia de los hijos se habría retrasado al nivel de lo que la sociedad considera deseable y aceptable. El hecho de tener los hijos demasiado joven no gozaría de una valoración social positiva, tal y como lo relata Almudena, que tuvo a su primer hijo con 26 años de edad - cinco años por debajo de lo que actualmente es la edad media a la maternidad al primer hijo, 31 años (INE, 2019b) —:

A mí me veían muy pequeña, muy jovencita y por eso me miraban raro. (Almudena [EP1])

La maternidad a edades avanzadas parece asociarse a mayor estabilidad laboral y económica, de modo que, socialmente, se habría generalizado la opinión de que las condiciones idóneas para la crianza de los hijos no se alcanzan sino hasta edades tardías:

Si hay una chica que es muy jovencita embarazada, igual piensas «a dónde vas cabeza loca», pero por eso mismo, porque las cosas no son fáciles, y a no ser que tengas una ayuda familiar a ese niño le va a faltar de todo. (Julia [EP7])

Por otro lado, también emerge la opinión acerca de una edad máxima para la tenencia de los hijos. Se trata de una creencia normativa acerca de lo que se espera socialmente:

El no tener hijos está sancionado de alguna manera cuando llegas a una edad (ella). Socialmente está un poco sancionado aunque no se diga abiertamente, pero la gente lo que piensa es «uy, es que no tienes hijos». Para un hombre también, pero es peor para mujeres (él). (Isabel [EP15])

En el caso de Gema, la presión social se percibe a través de preguntas procedentes de su entorno cercano. Su caso es de los pocos que relatan haber percibido una elevada presión social:

Sí, yo lo he pasado muy mal: «¡Ay! ¿ Todavía no te quedas embarazada? ¿Y por qué no te quedas embarazada?». (Gema [EP14])

\subsection{Dependencia de circunstancias externas e intención de aplazamiento del primer hijo: estabilidad laboral y económica}

La estabilidad en el ámbito laboral — que se asocia, a su vez, a la estabilidad económica - aparece continuamente en el discurso de los entrevistados como 
una condición prioritaria a la hora de lanzarse al proyecto de tener hijos. Se trata de una opinión recurrente en el discurso de todos los entrevistados. Veamos primero cómo emerge esta condición en el discurso de los que se encuentran en edades inferiores a los 30 años, como María, quien sencillamente no se plantearía tener un hijo hasta no haber alcanzado una situación de estabilidad profesional y, por tanto, económica; y como Pedro y Sandra, para quienes la estabilidad laboral constituye la base de la seguridad económica necesaria para la tenencia de un hijo:

Más que júnior o sénior en una empresa en el ámbito profesional, creo que aquello que te dé estabilidad, o sea, personalmente, yo nunca me plantearía, yo, tener hijos hasta que no tenga cierta estabilidad profesional, y sepa que no les va a faltar qué comer... (María [EP2])

Para plantearnos tener un hijo tendríamos que tener un trabajo estable los dos (ella). Yo diría que tener dinero, si nos toca el Euromillón también nos plantearemos tener un hijo. Yo creo que es eso, la base económica, y ya evidentemente con trabajo (él). (Sandra y Pedro [EP3])

Para María, la inestabilidad de su situación laboral constituye la barrera principal que le impide llegar a plantearse el proyecto de tener hijos. Su condición de becaria y la percepción de inestabilidad laboral en el futuro próximo ocupan sus preocupaciones vitales en el momento actual e inciden en la postergación obligada de las intenciones reproductivas:

[...] las condiciones económicas y laborales, ya que se asocia tener hijos a gente joven y nuestras condiciones no son las más sencillas. En mi caso, con 28 años, el otro día vi mi vida laboral: llevo cuatro años cotizando en la Seguridad Social, con un contrato de trabajo en el 2007 de un mes, el único trabajo con contrato que he realizado y fue en Zara. Creo que las condiciones de precariedad laboral que existen para las personas jóvenes no van a facilitar nunca que tengas hijos. [...] No me lo planteo ahora mismo también... Es cierto que con mi condición de becaria eterna no puedo plantearme nada más allá, casi que de vivir el día a día. Y yo, dentro de un mes, no sé si me renuevan o no contrato. No sé cuáles son mis circunstancias y mis planes a corto plazo, no voy a entrar nunca a tener hijos. (María [EP2])

Los riesgos que se asocian a la tenencia de un hijo sin haber alcanzado esa situación de estabilidad económica no son asumibles, en opinión de Pedro, y serían casi una muestra de irresponsabilidad:

La mayoría de gente, considero yo, no va a buscar tener un hijo hasta que no esté seguro, hasta no tener una situación estable, claro, no vas a tener un hijo sin trabajo, o sea, de verdad, que la gente de verdad no tenga hijos cuando no esté en una situación propicia para tener hijos, o sea, es de locos, qué vas a hacer, con qué le vas a alimentar. [...] Pero luego lo que pasa es que no tienes tantos hijos por eso. (Pedro [EP3]) 
Que la estabilidad laboral y económica constituyen una condición sine qua non para la tenencia de hijos es una opinión compartida por los entrevistados mayores de 30 años, como María José:

Pienso que en cuanto decides tener un hijo se supone que tienes ya un trabajo estable, $[\ldots]$ que cuando ya tienes una estabilidad económica es cuando decides tener un hijo. [...] Incluso has podido hablarlo en la empresa... (María José [EP11])

La búsqueda de estabilidad laboral y económica estaría incidiendo en el retraso de la llegada de los hijos:

La gente espera mucho a poder estabilizarse laboralmente, hasta que no llegue a unos ingresos [...]. La gente lo planea mucho. Entonces, al final, yo creo que se pasa la vida y... (Almudena [EP1])

Yo cuando era joven decía «mis hijos los quiero tener antes de los 30», lo tenía todo muy enfocado, «yo mis niños antes de los 30 , quiero tener tres» [...], pero según se van dando las circunstancias te das cuenta de que todo lo que planeas no sale. Mi ideal era tenerlos antes de los 30 para ser una madre joven, pues me di cuenta de los sueldos, de que no tenía pareja, etcétera. Pues he tenido que posponer, y me alegro, porque antes tampoco ganaba lo que gano ahora ni tenía esta situación de estabilidad. Hoy en día te lo marca un poco tu situación económica y personal, pero cada vez se está siendo mamá más tarde... (Cristina [EP4])

El alcance de la estabilidad laboral y económica considerada como necesaria para la tenencia de un hijo se ha retrasado de manera considerable, no solo por el largo período de formación que suponen los estudios hoy en día, sino por la lenta incorporación al mercado laboral:

[...] haces cuatro o cinco años de carrera, te plantas en los 23 , algo de especialización, dos años de máster, 25 años... Ponte que se te retrasa algo y te estás planteando los 27. Con 27 años y todavía no has empezado a trabajar... Para formar una familia necesitas un sustento económico. [...] Antes era más fácil, estabas trabajando, y a los 23 años ya habías estado trabajando, tenías unos ahorros y te podías plantear algo. Hoy veo gente que a los 27 años aún no ha tenido la experiencia con el mundo laboral o como mucho ha tenido una beca, unas prácticas. (Pedro [EP3])

Sin embargo, sabemos que en el modelo TPB aplicado a las intenciones reproductivas hay una distinción entre el control actual sobre las circunstancias de las que depende la decisión - es decir, las circunstancias objetivas, como la disposición de medios económicos, la vivienda, el estado de salud, etcéteray la percepción que se tiene de estas circunstancias. En este sentido, resulta de interés explorar cuál es la percepción de los entrevistados acerca del nivel económico que consideran necesario para la tenencia del primer hijo. 
El elevado coste que implican los hijos emerge en el discurso de los entrevistados, como Javier, quien considera que los salarios actuales no estarían a la altura requerida para asumir los gastos que implican los niños:

Tener dinero es una condición importante a día de hoy, ya que los sueldos no están a lo que te piden en la vida los niños. ¿Y los organizativos? Van de la mano del económico, si uno tiene dinero pues lo lleva mucho mejor, pero, si son mileuristas la madre y el padre, pues al final no puedes cambiar de casa y lo que supone todo lo demás, la comida, todo va unido. (Javier [EP13])

Almudena está de acuerdo en que actualmente el mayor freno para la tenencia de hijos es el económico, pero opina que esto se debe, en parte, al elevado estándar de calidad de vida que los padres quieren ofrecer a sus hijos:

Hoy en día, en la sociedad, el mayor freno a tener hijos es el económico. El principal es el económico, porque todo el mundo dice, puf, un hijo es mucha pasta en los colegios... actividades... Porque luego es tener hijos y querer que vayan a un colegio privado, que tengan lo mejor. (Almudena [EP1])

Para Carmen, poder ofrecer a sus hijos toda una serie de comodidades y beneficios materiales constituye una condición previa a la decisión de tener el primer hijo. David reconoce que, para él, disponer de buenos ingresos es fundamental, dado que no quiere renunciar a un nivel de calidad de vida, tanto para él como para sus hijos:

Los tendré si puedo comprar y ofrecer todo lo que yo quiero y crea oportuno, y estas cosas de poder pagarles el fútbol, el gimnasio, el ballet, el inglés, de llevarlos a un buen colegio. (Carmen [EPG])

[...] te metes en una calidad de vida de la que es difícil salir. Para mí, es muy importante tener los ingresos que tengo porque, si no, no podría ni darle la vida que yo quiero a mis hijos, ni yo llevar la calidad de vida que quiero. (David [EP10])

En general, las personas entre 25 y 45 años perciben que es necesario disponer de un buen nivel económico para poder asumir los gastos tan elevados que se asocian a la llegada de los hijos, y que responderían, al menos en parte, a toda una serie de requerimientos y exigencias percibidos como necesarios en el mundo de hoy:

[...] apúntalo a clases extraescolares y es otro dinero, luego campamentos en verano, luego queremos que los niños vayan a inglés, y llega un momento en que el niño está saturado y te saturas tú porque no llegas. (Gema [EP14])

Otros, como Martín y Cristina, reconocen que quieren ofrecer a sus hijos una buena calidad de vida, pero, por otro lado, son conscientes de que quizás hoy en día nos hayamos creado toda una serie de necesidades materiales que 
antes no existían, y que inciden en la configuración de las intenciones reproductivas:

El nivel económico, [...] cuando hablamos de económico, porque nosotros también queremos una vida para nuestros hijos (él). Sí, porque nos creamos necesidades que a lo mejor antaño no existían. Ahora hace falta tener 20 pares de zapatillas, no sé qué, la Play, la tal, y antes de eso no había, y a lo mejor pues la gente tenía más hijos... (ella). (Martín y Cristina [EP4])

En el discurso de los entrevistados, emergen otras condiciones que se asocian al retraso en la tenencia del primer hijo - como el retraso en la formación de pareja-, que por motivos de espacio no nos es posible profundizar aquí.

\section{Discusión}

El análisis de contenido de las entrevistas en profundidad nos ha permitido abordar las percepciones y las valoraciones más relevantes que estarían incidiendo en el retraso de la tenencia de los hijos - fundamentalmente el primeropara las personas entre 25 y 45 años de edad residentes en la Comunidad de Madrid. Como hemos podido ver, las decisiones reproductivas son complejas, ya que intervienen una amplia variedad de factores, tanto estructurales - económicos, laborales y de formación de pareja- como subjetivos, asociados a la prioridad otorgada a determinados valores y estilos de vida. Se trata de elementos procedentes de marcos teóricos distintos utilizados en la literatura a la hora de explorar las causas de la baja fecundidad. En este sentido, nuestros resultados están en la misma línea de Lebano y Jamieson (2020), quienes apuntan la necesidad de una aproximación teórica que permita dar cuenta de factores procedentes de distintas corrientes teóricas. El modelo teórico utilizado en este estudio para responder a la configuración de la intención de aplazamiento en la tenencia del primer hijo — la TPB — nos ha permitido indagar algunas hipótesis provenientes de otras aportaciones teóricas que confluyen en el nivel micro de las decisiones reproductivas, tal y como detallamos a continuación.

Las dos preguntas de investigación que nos planteábamos eran: [P1] si la percepción de costes o efectos negativos, de normas sociales y la dependencia de circunstancias externas incidían en la intención de aplazar la tenencia del primer hijo; y [P2] si, a su vez, la valoración personal que se atribuye al trabajo remunerado y a un estilo de vida altamente autónomo estaba incidiendo sobre las actitudes, normas y percepción de dependencia de otros factores, relacionados directamente con la intención de aplazamiento. A continuación discutimos los resultados a la luz de las hipótesis planteadas.

La H1 apuntaba hacia una mayor percepción de costes en el ámbito laboral remunerado derivados de la tenencia del primer hijo para las mujeres, lo cual contribuiría a configurar una actitud favorable a la intención de aplazamiento. En la línea de algunos estudios que han abordado la penalización por maternidad desde una perspectiva sociológica, nuestros resultados aportan 
evidencia cualitativa que apunta a una percepción de valoración negativa de las mujeres embarazadas o con niños pequeños respecto a la contratación y la renovación de contratos temporales, así como a devaluación de funciones y responsabilidades de las trabajadoras que anuncian su embarazo en el ámbito laboral, o que retornan de una baja por maternidad. Correll et al. (2007) ya habían encontrado evidencia que apuntaba que las mujeres que son madres son juzgadas como menos competentes y menos comprometidas que las mujeres sin hijos en un proceso de selección de personal, y González et al. (2019) habían aportado evidencia para España de que las mujeres con hijos tenían una menor probabilidad de recibir una llamada para una entrevista de trabajo que hombres de características comparables.

Nuestro estudio aporta evidencia parcial de que esta percepción de costes que traería consigo la llegada del primer hijo para la situación laboral de la mujer estaría incidiendo en el aplazamiento de la intención reproductiva. Parece que la decisión de aplazar difiere en función del nivel educativo y de la trayectoria y las expectativas de progresión laboral de las mujeres. Aquellas que, como Sandra (EP3), han mencionado explícitamente que esperan hasta haberse consolidado profesionalmente para tener su primer hijo son mujeres con nivel educativo alto y trayectoria laboral ascendente, que perciben la penalización por maternidad en términos de la mayor dificultad de acceder a puestos de responsabilidad. La percepción de penalización por parte de mujeres como Silvia (EP13) — con menor nivel educativo y una trayectoria laboral con interrupciones - lo es en términos del acceso y la estabilidad en un puesto de trabajo, sin entrar en consideraciones respecto a la progresión profesional.

La penalización que traería consigo la llegada de los hijos sobre el desarrollo profesional de la mujer es mayor hasta no haber alcanzado una situación de estabilidad en el trabajo, lo cual estaría incidiendo en el retraso del calendario reproductivo de las mujeres en España. Miller (2011a) ya había aportado evidencia acerca de los efectos positivos del retraso en la llegada de los hijos respecto a la evolución salarial de aquellas mujeres con estudios superiores y en ocupaciones profesionales y directivas. Estudios más recientes, como el de Doren (2019) para Estados Unidos, aportan evidencia acerca del prémium salarial por maternidad que experimentarían aquellas mujeres con nivel educativo alto que retrasan la tenencia del primer hijo más allá de los 30 años.

La percepción generalizada de los costes elevados que estaría afrontando la mujer por la tenencia de los hijos en el ámbito laboral remunerado hace que nos preguntemos por la sostenibilidad social de culturas laborales en las que no se apoya ni se promueve la conciliación real entre vida laboral y vida familiar. En línea con McDonald (2013), la baja fertilidad persistente sería una característica de sociedades donde las mujeres tendrían que hacer elecciones fuertes entre empleo y familia. La sociedad española parece ser una de ellas, dado que la percepción de incompatibilidad de la maternidad con una carrera profesional emerge como factor clave entre las razones por las que algunas mujeres españolas declaran no tener intención de tener hijos (Seiz, 2013). En esta misma línea, la reciente Encuesta de Fecundidad del INE (2018) señala que el $30 \%$ de las 
mujeres que retrasaron su maternidad lo hicieron por razones laborales, de conciliación de la vida familiar y laboral, y razones económicas.

$\mathrm{La} \mathrm{H} 2$ indagaba otro de los costes percibidos, que configurarían una actitud favorable al aplazamiento en la tenencia del primer hijo: los efectos negativos que previsiblemente traería la llegada del primer hijo en términos de la libertad de movimiento y de las opciones de ocio. Las entrevistas en profundidad aportan evidencia sustentando esta hipótesis: no querer renunciar a su independencia y a estilos de ocio asociados a una elevada facilidad de movimiento constituye uno de los factores centrales que emergen en el discurso de hombres y mujeres entre 25 y 40 años a la hora de explicar el retraso en la tenencia del primer hijo. La decisión de tenerlo implica efectuar una transición importante en el ciclo de vida: "hacerse mayor» y "sentar cabeza». En el imaginario de quienes no tienen hijos es como si todavía hubiese muchas cosas por hacer antes de dar el paso a la maternidad y a la paternidad, que se asocian, ciertamente, a asumir una responsabilidad definitiva, a la que muchos se refieren negativamente en términos de atadura. Nuestros resultados corroboran aportaciones anteriores de la literatura sobre la incidencia de la extensión de la juventud en el aplazamiento de la fecundidad (Gauthier y Charbonneau, 2002; Billari, 2004).

Pero el elemento de fondo que parece estar incidiendo en una elevada percepción de costes de la tenencia del primer hijo en términos de pérdida de libertad de movimiento y de opciones de ocio es la alta valoración de la autonomía individual (H5), reflejada, a su vez, en la preferencia por estilos de vida sin compromisos vinculantes definitivos, entre los que se cuenta la llegada de un hijo. La evidencia aportada a este respecto para el caso español se encontraría en la estela de la literatura sobre la "segunda transición demográfica» (Lesthaeghe, 1983; Surkyn y Lesthaeghe, 2004), en la que se otorga un papel preponderante al auge de la autonomía individual y de valores posmaterialistas - como la autorrealización personal - a la hora de explicar el cambio en los patrones de formación de las familias y de los comportamientos reproductivos, entre los que se encuentra el retraso en la tenencia de los hijos.

Pero tal y como ha señalado el propio Lesthaeghe (2010) —uno de los proponentes de la Teoría de la Segunda Transición Demográfica-, el cambio cultural constituiría una fuerza adicional a los factores económicos macro y micro de carácter estructural, a los que también les reconoce un impacto sobre la fecundidad. En esta dirección, la H4 recogía la influencia de aspectos económicos y laborales estructurales sobre las intenciones de aplazamiento de la tenencia de los hijos, y lo hacía abordando las percepciones en torno a la inestabilidad laboral y económica.

En línea con la literatura anterior, que aportaba evidencia acerca de la incidencia de la incertidumbre económica y laboral sobre el aplazamiento en la tenencia de los hijos (Kohler et al., 2002; Noguera et al., 2002; Kreyenfeld, 2009; Kreyenfeld et al., 2012), el análisis de contenido de las entrevistas en profundidad indica que la estabilidad laboral y económica constituye una condición común a todos los entrevistados de cara a plantearse la intención de tener un hijo. Las dificultades para encontrar una estabilidad laboral (y por 
tanto económica) que afrontan jóvenes como María (EP2) — con elevado nivel educativo, pero una trayectoria precaria de inserción profesional y con pocas perspectivas de mejora en el corto plazo- constituyen un factor relevante que incide en el retraso de la tenencia de los hijos, especialmente en países del sur de Europa, como España, con elevadas tasas de paro juvenil (Adsera, 2011).

Cuando se analiza cuál es la percepción del nivel económico requerido para la tenencia de un hijo, emergen dos elementos: por un lado, las declaraciones de algunos entrevistados apuntan al elevado coste objetivo que se requiere para cubrir las necesidades básicas del niño; por otro lado, algunos reconocen que quieren poder ofrecer a sus hijos un estándar alto de vida, lo cual eleva el listón del nivel económico percibido que se requiere para poder tener un hijo. Es probable que la percepción de estabilidad económica requerida como condición para las intenciones reproductivas esté siendo mediada por estos dos elementos: la dificultad objetiva de la pareja por alcanzar un nivel salarial que le permita mantener su nivel de vida y afrontar los gastos que implica el hijo, y el alto nivel de expectativas de lo que habría que poder ofrecer materialmente a los hijos.

En relación a la $\mathrm{H} 3$, referente a la incidencia de la presión social normativa sobre las intenciones de aplazamiento en la tenencia del primer hijo, nuestro trabajo arroja resultados distintos a los de estudios anteriores que habían utilizado la TPB como modelo en otros contextos (Billari et al., 2009; Dommermuth et al., 2011; Klobas y Ajzen, 2015; Ciritel et al., 2019). Aunque en línea con las aportaciones de Liefbroer y Billari (2010), parece que persisten ciertas normas sociales percibidas referentes a la edad mínima y máxima para la tenencia de los hijos. La percepción que prevalece es la de una flexibilización creciente de la presión social normativa procedente de la familia de origen - fundamentalmente los padres-y de los entornos más cercanos respecto a las decisiones reproductivas. En un ámbito como este, en el que las normas sociales parecen haberse diluido en comparación con el pasado, la autonomía individual constituye el elemento central. Esto estaría apuntando que, para el caso español, las tesis referentes a la segunda transición demográfica tendrían mucho que ver con los cambios en los comportamientos reproductivos, sobre todo con el aplazamiento en la tenencia de los hijos. En todo caso, una de las pocas presiones sociales percibidas que se recogen en las entrevistas tiene que ver más bien con una presión al aplazamiento. Sería de interés que otras investigaciones profundizaran en el impacto del comportamiento de los entornos sociales cercanos respecto a las decisiones referentes al tempo de la tenencia de los hijos para el caso español.

El modelo teórico TPB utilizado ha mostrado potencial para integrar distintos enfoques y aportaciones de la literatura sobre los determinantes de la fecundidad en las sociedades avanzadas, y ha abierto nuevas perspectivas acerca del modo en que interactúan factores subjetivos y objetivos del nivel micro con factores del contexto, pero nuestro estudio no carece de limitaciones.

En primer lugar, si bien todos los resultados de la investigación apuntan que las percepciones y valoraciones en torno a la penalización laboral por maternidad inciden sobre el tempo de la decisión de tener un hijo, sería nece- 
sario introducir mejoras en el diseño metodológico de la muestra de cara a determinar la incidencia específica de estos factores sobre la tenencia del primer hijo, en comparación a los siguientes. Para futuros estudios que se propongan afinar esta cuestión sería aconsejable: aumentar el número de casos de personas y parejas sin hijos y con un hijo, de cara a comparar las diferentes razones del aplazamiento en la progresión; y reducir la dispersión de los casos priorizando más bien variables socioeconómicas — como el estatus laboral-y sociodemográficas, como el modelo de familia (cohabitación o matrimonio), para la selección de los mismos.

En segundo lugar, al habernos centrado en los tres antecedentes directos de las intenciones de aplazamiento, solo hemos profundizado en la incidencia de algunos factores subjetivos del contexto, de manera que hemos dejado de lado en nuestro análisis factores objetivos de contexto - como el tipo de convivencia en pareja- que habrían de ser tenidos en cuenta en futuras investigaciones.

Asimismo, aunque entre los entrevistados teníamos tanto a hombres como a mujeres, el foco de atención sobre las consecuencias negativas de la tenencia de hijos en el ámbito laboral se desplazó espontáneamente hacia las mujeres, lo que indica que son ellas las que mayores dificultades siguen encontrando a la hora de conciliar ambos ámbitos. En futuros trabajos, en línea con JuradoGuerrero et al. (2018), habría que indagar en qué medida los hombres que empiezan a acceder a medidas de conciliación tras la llegada de los hijos experimentan consecuencias negativas en el ámbito laboral, que a su vez podrían repercutir sobre sus decisiones reproductivas.

\section{Conclusiones}

A partir del modelo teórico TPB aplicado a las decisiones reproductivas, este artículo aporta evidencia cualitativa en torno a las percepciones y las valoraciones más relevantes que inciden en la intención de aplazar la llegada del primer hijo entre las personas de 25 a 45 años de edad residentes en la Comunidad de Madrid. Centrándonos en el proceso micro de las decisiones reproductivas, hemos integrado aportaciones relevantes de distintos marcos teóricos que han abordado el aplazamiento en la tenencia de los hijos. Entre estas se incluyen las referentes a la penalización por maternidad, a la incidencia de factores macroeconómicos sobre la fecundidad y a la Teoría de la Segunda Transición Demográfica. Con ello, nos situamos en la línea de estudios cualitativos recientes, que también abordan el retraso en las decisiones reproductivas (Bueno y Brinton, 2019; Lebano y Jamieson, 2020) y que apuntan la necesidad de aproximaciones teóricas incluyentes, que permitan dar cuenta de la influencia de distintos factores.

Al tratarse del primer estudio que, hasta donde sabemos, emplea el modelo TPB en el contexto español para estudiar las intenciones de aplazamiento de la tenencia del primer hijo, nuestros resultados representan una aportación de cara a futuros estudios sobre el tema — también de carácter cuantitativo-, al haber hecho una aproximación inicial a las percepciones y las valoraciones 
relevantes en la configuración de las intenciones reproductivas referentes al tempo para el contexto español.

Hemos señalado que los elevados costes percibidos de la tenencia del primer hijo para la mujer en el terreno laboral estarían incidiendo en la intención de aplazamiento, fundamentalmente en aquellos casos de mujeres con nivel educativo alto y una carrera profesional ascendente, que priorizan su realización personal en este ámbito y desean alcanzar una alta progresión profesional. En todo caso, las declaraciones de todos los entrevistados apuntan que la cultura social y laboral dominante no estaría ofreciendo las condiciones necesarias para que el desarrollo inicial de una carrera profesional se perciba como algo compatible con la tenencia de los hijos para las mujeres.

Nuestros resultados también han indicado que la elevada percepción de costes de la llegada del primer hijo en términos de libertad de movimiento y de opciones de ocio está incidiendo en las intenciones de retraso, tanto en el caso de hombres como de mujeres. En línea con las aportaciones de la literatura sobre la segunda transición demográfica y sobre la extensión de la juventud, esta percepción estaría mediada por la alta valoración que se atribuye a la autonomía personal y al deseo de alargar la etapa vital en la que no se tienen compromisos ni responsabilidades vinculantes de carácter definitivo.

En relación directa con la prioridad que adquiere la autonomía individual y de la pareja en las decisiones reproductivas de aplazamiento, no parece que las normas sociales percibidas estén desempeñando un papel relevante en las intenciones de aplazamiento, aunque se presenta cierta evidencia acerca de la existencia de normas de edad, que marcarían una edad mínima cada vez más elevada para la tenencia de los hijos.

En línea con la literatura anterior sobre la relación entre factores macroeconómicos y fecundidad, la estabilidad laboral y económica se percibe como una condición esencial para dar el paso a la tenencia del primer hijo en el contexto español. Nuestro estudio hace una aportación específica a este respecto, al apuntar que la estabilidad económica percibida no solo depende de factores objetivos - como tener un trabajo estable-, sino también de factores subjetivos, como la existencia de un umbral elevado del nivel de bienestar material que supuestamente habría que poder ofrecer a los hijos.

Entender que las decisiones reproductivas de las personas y de las familias son complejas y multifactoriales, en las que inciden no solo las condiciones objetivas del contexto económico y social, sino también los valores, las percepciones y las preferencias, resulta del todo relevante en un contexto demográfico como el que se ha venido configurando en España, de fecundidad muy baja y de transición tardía a la maternidad y a la paternidad. Chocando con la lógica biológica y de salud, parece que no solo las lógicas social y económica abogarían por tener los hijos más tarde (Beaujouan y Sobotka, 2017), sino también la lógica de los valores, que habría transitado hacia una comprensión de la libertad en términos de autonomía absoluta y de autorrealización individual, lo que lleva a postergar cada vez más la asunción de compromisos vinculantes y de opciones vitales definitivas, entre las que estaría la llegada de un hijo. 


\section{Agradecimientos}

A los dos evaluadores anónimos que participaron en el proceso de revisión del artículo, cuyas aportaciones y observaciones contribuyeron notablemente a mejorar la calidad del mismo | A María Teresa López López, por el impulso dado a una investigación rigurosa y de calidad en temas de familia.

\section{Financiación}

La realización de las entrevistas en profundidad se llevó a cabo gracias a la financiación de la ONG Acción Familiar, en el marco del proyecto de investigación sobre la relación familia-trabajo llevado a cabo entre 2017 y 2019.

\section{Referencias bibliográficas}

Adsera, Alicia (2011). «Where Are the Babies? Labor Market Conditions and Fertility in Europe». European Journal of Population / Revue Européenne de Démographie, $27(1), 1-32$. <https://doi.org/10.1007/s10680-010-9222-x>

Ajzen, Icek (2002). «Perceived Behavioral Control, Self-Efficacy, Locus of Control, and the Theory of Planned Behavior». Journal of Applied Social Psychology, 32 (4), 665-683. <https://doi.org/10.1111/j.1559-1816.2002.tb00236.x>

Alvarez, Bruna (2018). «Reproductive Decision Making in Spain: Heterosexual Couples' Narratives About How They Chose to Have Children». Journal of Family Issues, 39 (13), 3.487-3.507. $<$ https://doi.org/10.1177/0192513X18783494>

Bachrach, Christine A. y Morgan, S. P. (2011). «Further reflections on the Theory of Planned Behaviour and fertility research». Vienna Yearbook of Population Research, 9, 71-74. $<$ https://doi.org/10.1553/populationyearbook2011s71>

Balbo, Nicoletta; Billari, Francesco C. y Mills, Melinda (2013). «Fertility in Advanced Societies: A Review of Research». European Journal of Population / Revue Européenne de Démographie, 29 (1), 1-38. <https://doi.org/10.1007/s10680-012-9277-y>

Beaujouan, Éva y Sовотка, Tomáš (2017). «Late motherhood in low-fertility countries: Reproductive intentions, trends and consequence». Vienna Institute of Demography Working Papers (02/2017).

Billari, Francesco (2004). «Becoming an Adult in Europe: A Macro(/Micro)-Demographic Perspective». Demographic Research, S3, 15-44. <https://doi.org/10.4054/DemRes.2004.S3.2>

Billari, Francesco y Kohler, Hans-Peter (2004). «Patterns of low and lowest-low fertility in Europe». Population Studies, 58 (2), 161-176. <https://doi.org/10.1080/0032472042000213695>

Billari, Francesco C.; Philipov, Dimiter y Testa, Maria R. (2009). «Attitudes, Norms and Perceived Behavioural Control: Explaining Fertility Intentions in Bulgaria». European Journal of Population / Revue Européenne de Démographie, 25 (4), 439. <https://doi.org/10.1007/s10680-009-9187-9> 
Bueno, Xiana y Brinton, Mary C. (2019). «Gender egalitarianism, perceived economic insecurity, and fertility intentions in Spain: A qualitative analysis». Population Studies, 73 (2), 247-260. <https://doi.org/10.1080/00324728.2019.1604979>

Castro Martín, Teresa; Martín García, Teresa; Cordero, Julia y Seiz, Marta (2018). «El desafío de la baja fecundidad en España». En: Blanco, Agustín; ChueCA, Antonio; López-Ruiz, José A. y Mora, Sebastián (eds.). Informe España 2018. Salamanca, 164-228.

Ciritel, A.-A.; Rose, A. de y Arezzo, M. F. (2019). "Childbearing intentions in a low fertility context: the case of Romania». Genus, 75 (1). <https://doi.org/10.1186/s41118-018-0046-6>

Correll, Shelley J.; Benard, Stephen y Paik, In (2007). «Getting a Job: Is There a Motherhood Penalty?». American Journal of Sociology, 112 (5), 1.297-1.339. $<$ https://doi.org/10.1086/511799>

Delgado, M.; Rose, A. de; Barrios, L. y Lopez, F. Z. (2009). «The delay of maternity and its causes: An analysis of the timing of the first child in Spain». Genus, 65 (2), 79-111.

Dommermuth, L.; Klobas, J. y LappegÅrd, T. (2011). "Now or later? The Theory of Planned Behavior and timing of fertility intentions». Advances in Life Course Research, 16 (1), 42-53. <https://doi.org/10.1016/j.alcr.2011.01.002>

Doren, Catherine (2019). «Which Mothers Pay a Higher Price? Education Differences in Motherhood Wage Penalties by Parity and Fertility Timing». Sociological Science, 6, 684-709. <https://doi.org/10.15195/v6.a26>

Eurostat (2020). "Database: Fertility». Últimos datos publicados. <https://ec.europa.eu/eurostat $/ \mathrm{tgm} / \mathrm{table} . \mathrm{do}$ ?tab=table \&init $=1 \&$ language $=$ en $\&$ pcode $=\mathrm{t}-$ ps00017\&plugin $=1>$.

FaHlén, Susanne y OláH, Livia S. (2018). «Economic uncertainty and first-birth intentions in Europe». Demographic Research, 39, 795-834. <https://doi.org/10.4054/DemRes.2018.39.28>

Gauthier, Madeleine y Charbonneau, Johanne (2002). Jeunes et fécondité les facteurs en cause: Revue de la littérature et synthèse critique. Montreal: Institut National de la Recherche Scientifique, Urbanisation, Culture et Société.

González, María-José; Cortina, Clara y Rodríguez, Jorge (2019). «The Role of Gender Stereotypes in Hiring: A Field Experiment». European Sociological Review, 35 (2), 187-204. <https://doi.org/10.1093/esr/jcy055>

Gustafsson, Siv (2001). "Optimal age at motherhood. Theoretical and empirical considerations on postponement of maternity in Europe». Journal of Population Economics, 14 (2), 225-247. <https://doi.org/10.1007/s001480000051>

- (2005). "Having Kids Later. Economic Analyses for Industrialized Countries». Review of Economics of the Household, 3 (1), 5-16. <https://doi.org/10.1007/s11150-004-0977-x>

INE (2018). «Encuesta de Fecundidad 2018: datos agregados». <http://www.ine.es/dyngs/ INEbase/es/operacion.htm?c=Estadistica_C\&cid=1254736177006\&menu=resultados\&idp $=1254735573002>$.

- (2019a). «Estadística de nacimientos: movimiento natural de la población». 
<http://www.ine.es/dyngs/INEbase/es/operacion.htm?c=Estadistica_C\&cid $=1254736177007 \&$ menu $=$ resultados\&idp $=1254735573002>$.

- (2019b). "Indicadores demográficos básicos: natalidad y fecundidad». <https://www.ine.es/dyngs/INEbase/operacion.htm?c=Estadistica_C\&cid $=1254736177003 \&$ menu $=$ resultados $\&$ secc $=1254736195380 \&$ idp $=1$ 254735573002\#!tabs-1254736195380>.

Jurado-Guerrero, Teresa; Montferrer, Jordi M.; Botía-Morillas, Carmen y Abril, Francisco (2018). «Formal and Informal Workplace Support for New Fathers in Spain». En: Musumeci, Rosy y Santero, Arianna (eds.). Fathers, childcare and work: Cultures, practices and policies (primera edición). Bingley, UK: Emerald Publishing, 131-153.

Klobas, Jane E. y Ajzen, Icek (2015). «Making the Decision to Have a Child». En: Philipov, Dimiter; Liefbroer, Aart C. y Klobas, Jane E. (eds.). Reproductive Decision-Making in a Macro-Micro Perspective. Dordrecht: Springer Netherlands, 41-78. <https://doi.org/10.1007/978-94-017-9401-5_3>

Kohler, Hans-Peter; Billari, Francesco C. y Ortega, José A. (2002). "The Emergence of Lowest-Low Fertility in Europe During the 1990s». Population and Development Review, 28 (4), 641-680. <https://doi.org/10.1111/j.1728-4457.2002.00641.x>

Kreyenfeld, Michaela (2009). «Uncertainties in Female Employment Careers and the Postponement of Parenthood in Germany». European Sociological Review, 26 (3), 351-366. <https://doi.org/10.1093/esr/jcp026>

Kreyenfeld, Michaela; Andersson, Gunnar y Pailhé, Ariane (2012). «Economic Uncertainty and Family Dynamics in Europe». Demographic Research, 27, 835852 . <https://doi.org/10.4054/DemRes.2012.27.28>

Lebano, A. y Jamieson, L. (2020). «Childbearing in Italy and Spain: Postponement Narratives». Population and Development Review, 46 (1), 121-144. <https://doi.org/10.1111/padr.12313>

Lesthaeghe, Ron (1983). "A Century of Demographic and Cultural Change in Western Europe: An Exploration of Underlying Dimensions». Population and Development Review, 9 (3), 411-435. <https://doi.org/10.2307/1973316>

- (2010). «The Unfolding Story of the Second Demographic Transition». Population and Development Review, 36 (2), 211-251. <https://doi.org/10.1111/j.1728-4457.2010.00328.x>

Liefbroer, Aart C. (2011). "On the usefulness of the Theory of Planned Behaviour for fertility research». Vienna Yearbook of Population Research, 9, 55-62. <https://doi.org/10.1553/populationyearbook2011s55>

Liefbroer, Aart C. y Billari, Francesco C. (2010). «Bringing norms back in: a theoretical and empirical discussion of their importance for understanding demographic behaviour». Population, Space and Place, 16 (4), 287-305. <https://doi.org/10.1002/psp.552>

Liefbroer, Aart C.; Klobas, Jane E.; Philipov, Dimiter y Ajzen, Icek (2015). «Reproductive Decision-Making in a Macro-Micro Perspective: A Conceptual Framework». En: Philipov, Dimiter; Liefbroer, Aart C. y Klobas, Jane E. (eds.). 
Reproductive Decision-Making in a Macro-Micro Perspective. Dordrecht: Springer Netherlands, 1-15. <https://doi.org/10.1007/978-94-017-9401-5_1>

López López, María T. y González Hincapié, Viviana (2017). Tener hijos, eforma parte del proyecto vital de los madrileños?: Maternidad, paternidad y trabajo remunerado en la Comunidad de Madrid. 2017. Madrid: Cinca $<$ https://eprints.ucm.es/55537/>

Matysiak, A.; Sobotka, T. y Vignoli, D. (2020). «The Great Recession and Fertility in Europe: A Sub-national Analysis». European Journal of Population. <https://doi.org/10.1007/s10680-020-09556-y>

McDonald, Peter (2013). «Societal foundations for explaining fertility: Gender equity». Demographic Research, S16 (34), 981-994. <https://doi.org/10.4054/DemRes.2013.28.34>

Miller, Amalia R. (2011a). "The effects of motherhood timing on career path». Journal of Population Economics, 24 (3), 1.071-1.100. <https://doi.org/10.1007/s00148-009-0296-x>

Miller, Warren B. (2011b). «Differences between fertility desires and intentions: implications for theory, research and policy». Vienna Yearbook of Population Research, 9, 75-98. <https://doi.org/10.1553/populationyearbook2011s75>

Miller, Warren B. y Pasta, David J. (1994). «The Psychology of Child Timing: A Measurement Instrument and a Model». Journal of Applied Social Psychology, 24 (3), 218-250. <https://doi.org/10.1111/j.1559-1816.1994.tb00580.x>

Morgan, S. P. y Bachrach, Christine A. (2011). «Is the Theory of Planned Behaviour an appropriate model for human fertility?». Vienna Yearbook of Population Research, 9, 11-18. <https://doi.org/10.1553/populationyearbook2011s11>

Noguera, Carles S.; Golsch, Katrin y Steinhage, Nikolei (2002). «Increasing uncertainty in the Spanish labor market and entry into parenthood». Genus, 58 (1), 77-119.

Philipov, Dimiter; Liefbroer, Aart C. y Klobas, Jane E. (eds.) (2015). Reproductive Decision-Making in a Macro-Micro Perspective. Dordrecht: Springer Netherlands.

Rica, Sara de la e Iza, Amaia (2005). "Career Planning in Spain: Do Fixed-term Contracts Delay Marriage and Parenthood?». Review of Economics of the Household, 3 (1), 49-73. <https://doi.org/10.1007/s11150-004-0979-8>

Sampedro, Rosario; Gómez, M. V. y Montero, Mercedes (2002). «Maternidad tardía: incidencia, perfiles y discursos». Empiria. Revista de Metodología de Ciencias Sociales, 0 (5), 11.

<https://doi.org/10.5944/empiria.5.2002.911>

SeIz, Marta (2013). "Voluntary Childlessness in Southern Europe: The Case of Spain». Population Review, 52 (1), 110-128. <https://doi.org/10.1353/prv.2013.0006>

Surkyn, Johan y Lesthaeghe, Ron (2004). "Value Orientations and the Second Demographic Transition (SDT) in Northern, Western and Southern Europe: An Update». Demographic Research, S3, 45-86. <https://doi.org/10.4054/DemRes.2004.S3.3> 
Valles Martínez, Miguel S. (2009). Técnicas cualitativas de investigación social: Reflexión metodológica y práctica profesional. Madrid: Síntesis.

Vidal-Coso, Elena y Miret-Gamundi, Pau (2017). «Características de las madres primerizas y de los padres primerizos en la España del siglo Xxi / Characteristics of First-time Parents in Spain along the $21^{\text {st }}$ Century». Revista Española de Investigaciones Sociológicas.

<https://doi.org/10.5477/cis/reis.160.115> 